\title{
Seagrass Meadows Modify Drag Forces on the Shell of the Fan Mussel Pinna nobilis
}

\author{
Iris E. Hendriks • Miguel Cabanellas-Reboredo • \\ Tjeerd J. Bouma $\cdot$ Salud Deudero $\cdot$ Carlos M. Duarte
}

Received: 21 August 2009/Revised: 22 March 2010 / Accepted: 11 May 2010 /Published online: 4 June 2010

(C) The Author(s) 2010. This article is published with open access at Springerlink.com

\begin{abstract}
We assess the sheltering effect of Posidonia oceanica meadows on drag forces exerted on shells of the fan mussel Pinna nobilis. We examine a range of shell sizes under four unidirectional flow speeds $\left(0.05-0.34 \mathrm{~m} \mathrm{~s}^{-1}\right)$ and two oscillating regimes. Three meadow densities are evaluated and a control without vegetation. We found that the attenuating effect of the meadow on drag forces experienced by bivalves is determined by the form of the hydrodynamic energy, e.g., as unidirectional flow or wave action. In tidal currents, the meadow protects most sizes of bivalves, with a higher efficiency for dense meadows, while in wave dominant zones the meadow reduces drag forces for bivalves with shell areas below a threshold of $0.019 \mathrm{~m}^{2}$, whereas larger animals experience increased drag forces within the meadow independent of meadow density. Reduction of shoot density in seagrass meadows might
\end{abstract}

\section{E. Hendriks $(\bowtie) \cdot$ C. M. Duarte}

Department of Global Change Research. IMEDEA (CSIC-UIB),

Instituto Mediterráneo de Estudios Avanzados,

C/Miquel Marqués 21,

07190 Esporles (Mallorca), Spain

e-mail: iris@imedea.uib-csic.es

M. Cabanellas-Reboredo

Department of Ecology and Marine Resources. IMEDEA

(CSIC-UIB), Instituto Mediterráneo de Estudios Avanzados,

C/Miquel Marqués 21,

07190 Esporles (Mallorca), Spain

\section{T. J. Bouma}

Netherlands Institute of Ecology (NIOO),

Korringaweg 7 ,

4401 NT Yerseke, The Netherlands

\section{S. Deudero}

Instituto Español de Oceanografía (IEO) -

Centro Oceanográfico de Baleares,

muelle de Poniente s/n, apartado 291,

Plama de Mallorca 07015, Spain therefore not affect the effectiveness of the canopy to reduce drag forces on associated species like the fan mussel in wave-dominated areas while increased storm frequency could result into losses of larger individuals during periods of high wave action.

Keywords Seagrass $\cdot$ Posidonia oceanica $\cdot$ Fan mussel Pinna nobilis · Drag forces · Wave exposure

\section{Introduction}

Seagrass meadows are unique, productive, and highly diverse ecosystems, which provide habitat and food for organisms (Hemminga and Duarte 2000). Their lush canopies provide habitat and shelter to associated organisms. They also modify the abiotic environment, changing sedimentation rates (Gacia and Duarte 2001; Hendriks et al. 2008) and hydrodynamics above their canopies by modifying flow and turbulence and attenuating wave action (Ackerman and Okubo 1993; Gambi et al. 1990; Koch et al. 2006; Koch and Gust 1999; Nepf and Vivoni 2000; Peterson et al. 2004). Seagrass meadows can, therefore, provide shelter from water flow caused by wind waves or tides and increase the particle supply to associated filter feeders.

The fan mussel Pinna nobilis (Linnaeus, 1758) is one of the largest mollusc species, reaching total anterio-posterior lengths of up to $1.2 \mathrm{~m}$ (García-March et al. 2007a; Richardson et al. 1999; Zavodnik et al. 1991). The species is endemic to the Mediterranean Sea, where it typically occurs in association with Posidonia oceanica meadows, and is long-lived, achieving life spans in excess of 20 years (Butler et al. 1993; Galinou-Mitsoudi et al. 2006; Richardson et al. 1999). Fan mussels live partially buried upright in the sand, anchored by their numerous byssus filaments to the rhizomes and shoots of $P$. oceanica. 
The population numbers of the bivalve $P$. nobilis are currently in decline (Centoducati et al. 2007), and the fan mussel is subject to strict protection as an endangered species under the European Council Directive 92/43/EEC (EEC 1992). This decline has been ascribed to both an increase in anthropogenic impacts on coastal areas resulting from increased human population growth and incidental damages by trawling and anchoring and collection by divers (Katsanevakis 2007; Richardson et al. 2004; Zavodnik et al. 1991). In addition to these direct factors causing Pinna decline, indirect effects like interactions with invasive species (Box et al. 2009) and the widespread decline of its common habitat, P. oceanica (Marbà et al. 1996; Marba et al. 2005), may also be a major cause for the demise of this bivalve species. In particular, thinning of the seagrass meadows experiencing decline may reduce the shelter their canopies offer to P. nobilis. However, the role of seagrass meadows in providing shelter from wave forces to $P$. nobilis has not yet been assessed.

Stiff subtidal epibenthic organisms like $P$. nobilis may experience high drag forces $\left(F_{\mathrm{d}}\right)$ from oscillatory water movement produced by waves (García-March et al. 2007b). These forces on the protruding part of the organism are proportional with its size and can dislodge shells during storms with mortality as a result (García-March et al. 2007b). By attenuating hydrodynamic energy (Hendriks et al. 2008), Posidonia meadows can provide hydrodynamic shelter for stiff epibenthic species like $P$. nobilis. Hydrodynamic attenuation by seagrass meadows will strongly depend on meadow properties like shoot density and leaf length (Gambi et al. 1990; Nepf 1999). Although hydrodynamic facilitation of $P$. nobilis by seagrass meadows appears to be a likely explanation for the association of this species with $P$. oceanica meadows, quantitative understanding of how hydrodynamic sheltering depends on the combination of shell size, canopy properties, and hydrodynamic forcing is still lacking. Here, we assess the effect of $P$. oceanica meadows on drag forces exerted on individual $P$. nobilis shells. We do so under different unidirectional as well as oscillating flow speeds and evaluating the role of meadow density and bivalve size.

\section{Materials and Methods}

Seagrass Meadow P. oceanica shoots were collected in February 2008 from a meadow at Cala Estancia (Majorca, Spain) at 5-m depth, packaged, and immediately transported in a refrigerated container to the flume facility located at NIOO-KNAW, Yerseke, The Netherlands. The shoots were planted in the test section (dimensions 2.1-m long $\times 0.6-\mathrm{m}$ wide) with shoot densities of 0 (control), 221 (low density (LD)), 491 (medium density (MD)), and 808 (high density (HD)) shoots $\mathrm{m}^{-2}$ over the full length and width of the test section, corresponding to 1,143 (LD), 2,536 (MD), and 4,171 (HD) leaves $\mathrm{m}^{-2}$, respectively. At field sites, densities were recorded from 384 to 1,013 shoots $\mathrm{m}^{-2}$ (average 676 shoots $\mathrm{m}^{-2}$ ). Above ground biomass (leaves, dry weight) of the experimental meadows was 109 (LD), 202 (MD), and 322 (HD) $\mathrm{g} \mathrm{DW} \mathrm{m}^{-2}$. The shoots averaged $0.19 \pm 0.009$ (SE) $\mathrm{m}(n=129)$ in leaf length, but the flexible canopy bent at high unidirectional velocities, leading to effective canopy heights below the average leaf height. Water temperature was maintained at $14.5 \pm 0.31{ }^{\circ} \mathrm{C}$ (SE), comparable to that at the site of collection, while salinity was around $34 \%$. The seagrass meadow was planted in the test section on silica sand, with a grain size of $2<x>0.25 \mathrm{~mm}(96.9 \%)$, which was used as control treatment without vegetation.

Bivalves We used undamaged valves of $P$. nobilis, discarded from an experiment where the whole organism was extracted (Cabanellas-Reboredo et al. 2009) to reconstruct a natural mimic of our test organism. The valves were cut at one-third of the length from the posterior end, thereby removing the shell area typically buried in the sediment (Richardson et al. 1999; Zavodnik et al. 1991). We filled the cavity with twocomponent putty up to where the organism's mantle would have reached and inserted a screw in the now flat bottom. With this screw, the valves were mounted on a force transducer, which was incorporated in the Posidonia meadow at app. $2 \mathrm{~m}$ from the leading edge. The inflection point of the bivalves was at the height of the sediment in the seagrass meadow. The valves of $P$. nobilis have a triangular shape, with the largest surface area on the lateral side of the shell and a much narrower area on the dorso-ventral side. Young individuals have a range of cylindrical roughness features, about $5 \mathrm{~mm}$ in length, on the top part of the lateral side of the shells, while these have disappeared in larger, and older, individuals. The surface area of the lateral side of the shells was calculated with image analyses software ImageJ, while the area of the dorso-ventral side was calculated as $H \times$ $T$ (shell height $\times$ shell thickness). We used 13 Pinna shells mounted in this way, ranging in emergent surfaces (two-third of the shell) of 0.003 to $0.054 \mathrm{~m}^{2}$ (Table 1; Fig. 1a). The effect of shell orientation was tested by mounting the shell sideways $\left(0^{\circ}\right)$, turned halfway $\left(45^{\circ}\right)$, and perpendicular to the waves $\left(90^{\circ}\right)$. For unidirectional flow, we used only one shell in every size class, giving a total of five mounted shells, with the shells mounted at a $90^{\circ}$ orientation to the direction of flow (Fig. 1b).

Hydrodynamics The NIOO flume channel (circumference of $17.55 \mathrm{~m}$, width $0.60 \mathrm{~m}$ ) is equipped with both a wave paddle with a fly-wheel construction to generate regular sinusoidal waves and a conveyer belt to generate unidirectional flow. A more detailed description and diagram of the flume facility at the Netherlands Institute of Ecology in 
Table 1 Dimensions of Pinna nobilis shells used in this study

Pinna no. Width (m) Height (m) Thickness (m) Surface area $\left(\mathrm{m}^{2}\right)$

\begin{tabular}{lllll}
\hline 29 & 0.048 & 0.073 & 0.015 & 0.003 \\
1 & 0.055 & 0.085 & 0.015 & 0.005 \\
2 & 0.055 & 0.093 & 0.015 & 0.005 \\
3 & 0.07 & 0.094 & 0.02 & 0.006 \\
4 & 0.08 & 0.127 & 0.022 & 0.011 \\
5 & 0.045 & 0.075 & 0.017 & 0.003 \\
6 & 0.05 & 0.069 & 0.013 & 0.004 \\
7 & 0.065 & 0.082 & 0.017 & 0.005 \\
8 & 0.08 & 0.096 & 0.02 & 0.008 \\
9 & 0.087 & 0.075 & 0.022 & 0.010 \\
10 & 0.15 & 0.23 & 0.044 & 0.034 \\
11 & 0.142 & 0.243 & 0.041 & 0.032 \\
12 & 0.157 & 0.248 & 0.044 & 0.035 \\
14 & 0.185 & 0.298 & 0.055 & 0.054 \\
\hline
\end{tabular}

Yerseke can be found in Bouma et al. (2005) and is available at http://www.nioo.knaw.nl/science/facilities/flume/ flume.htm. We used 2 wave regimes, with wave generator speeds of 900 and $1,800 \mathrm{rmp}$, with a frequency $(f)$ of 0.36 and $0.67 \mathrm{~Hz}(T=2.8$ and $1.5 \mathrm{~s}$ resp.) and resulting wave heights $(H)$ of 0.04 and $0.08 \mathrm{~m}(n=10$, time series of $60 \mathrm{~s})$. Waves would be the predominant situation encountered by populations of $P$. nobilis in their natural environment. For instance, the nearest wave data-register point to the author's institute (Bay of Palma, WANA 2069036, 39.500 N; 2.625 E) of the Spanish Port Authority reports wave periods $\left(T_{\mathrm{p}}\right)$ of around $3 \mathrm{~s}$ (1-s intervals) for $27 \%$ of the data points collected during the year of the experiment (2008) while $68 \%$ has a higher $T_{\mathrm{p}}$.

Vertical flow profiles under control circumstances (no seagrass) and around $1.9 \mathrm{~m}$ from the leading edge in the meadow were measured with a Nortek Acoustic Doppler Velocimeter, mounted on a $3 \mathrm{D}$ positioning system. We investigated four unidirectional flow speeds, with free stream velocities $U_{\infty}$ of $0.05,0.10,0.25$, and $0.34 \mathrm{~m} \mathrm{~s}^{-1}$, and compared the increasing drag forces on Pinna shells to the control situation with no water movement.

Drag Measurements The drag force imposed on the Pinna shells was measured with a force transducer connected to a datalogger (cf. Bouma et al. 2005). The force transducer was calibrated using known weights, to express the drag forces exercised on the shells in Newton $\left(F_{\mathrm{d}}, \mathrm{N}\right)$. We divided the measured drag force by the surface area of each shell to compare shells of different sizes (specific drag force $F_{\mathrm{d}}{ }^{\prime}$; Newton per square meter). We calculated the attenuation of $F_{\mathrm{d}}{ }^{\prime}$ by Posidonia meadows of different density, by using control drag measurements on shells in the absence of vegetation (i.e., $F_{\mathrm{d} \text {-sand }}-F_{\mathrm{d}}^{\prime}$-meadow ). When measuring under continuous flow, $F_{\mathrm{d}}{ }^{\prime}$ was calculated from the timeaverage voltage readings, while for waves we derived $F_{\mathrm{d}}{ }^{\prime}$ as the amplitude of the signal of the force transducer as determined from the wave spectrum using the software package Auke PC.

For unidirectional flow, we examined the drag forces on five Pinna shells mounted in P. oceanica meadows with three increasing shoot densities and bare sand. Under lowenergy wave regimes $(900 \mathrm{rpm})$, we measured the drag forces on 13 Pinna shells with increasing surface areas in $P$. oceanica meadows with three shoot densities. Additionally, we tested the effect of orientation $\left(0^{\circ}, 45^{\circ}\right.$, and $90^{\circ}$ to the main flow direction) for five Pinna shells. We repeated this for a high-energy wave regime in one meadow with high shoot density (HD).

\section{Results}

Unidirectional Flow Drag forces $\left(F_{\mathrm{d}}{ }^{\prime}\right.$; Newton per square meter) on the shells ranged from $0.0001 \mathrm{~N}$ under slow flow
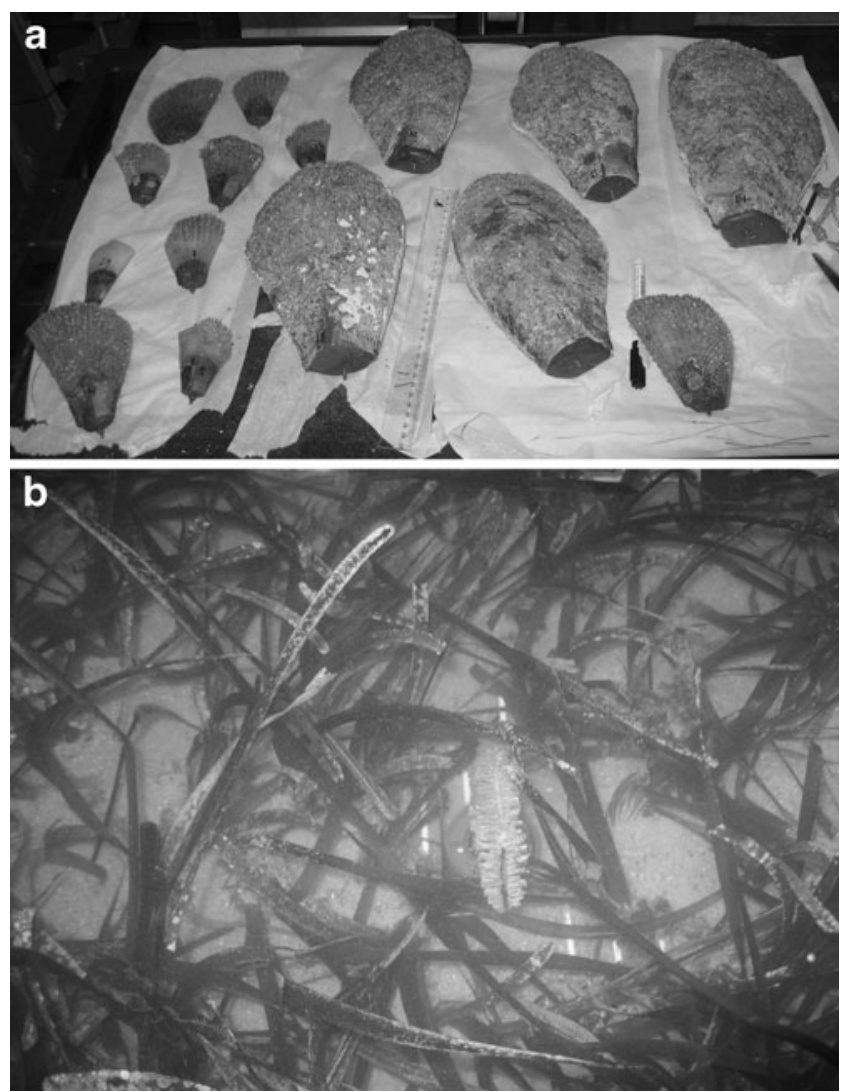

Fig. 1 a Reconstructed Pinna shells with exposed surface area ranging from 0.003 to $0.054 \mathrm{~m}^{2}$. b Small shell of $P$. nobilis $\left(0.005 \mathrm{~m}^{2}\right.$ surface area) mounted perpendicular to the flow direction in a meadow of MD live $P$. oceanica, planted in the test section of the flume canal. The meadow is $2.1-\mathrm{m}$ long $\times 0.6-\mathrm{m}$ wide (full width and length of the test-section of the flume canal) 
speeds $\left(0.05 \mathrm{~m} \mathrm{~s}^{-1}\right)$ to $7.952 \mathrm{~N}$ under high flow speeds of $U_{\infty}=0.34 \mathrm{~m} \mathrm{~s}^{-2}$. The forces per square meter shell surface $F_{\mathrm{d}}{ }^{\prime}$ (Newton per square meter) increased with increasing flow speeds (Fig. 2) when no vegetation was present.

Flow speed $(p<0.001)$, shell size $(p<0.01)$, and meadow density $(p=0.04)$ all have a significant effect on drag attenuation by the meadow on Pinna individuals $\left(\mathrm{GLM}_{d f=4}\right.$ $\left.\chi^{2}=25.47 ; p<0.001\right)$. For small shells $\left(<0.011 \mathrm{~m}^{2}, 0.08 \mathrm{~m}\right.$ shell width) and flow velocities $\geq 0.01 \mathrm{~m} \mathrm{~s}^{-1}$, the canopyattenuated drag forces, drag forces on the shells, were on average $11.09( \pm 2.558 \mathrm{SE}) \mathrm{N} \mathrm{m}^{-2}$ lower, corresponding to app. $18 \%$ of control (bare sand) values in low-density meadows, $15.27( \pm 3.789 \mathrm{SE}) \mathrm{N} \mathrm{m}^{-2}(25 \%)$ in medium density meadows; with higher efficiency in dense meadows, where drag forces were $17.82( \pm 4.512 \mathrm{SE}) \mathrm{N} \mathrm{m}^{-2}$ lower or, otherwise stated, $17 \%$ of control values. Under low flow velocities $\left(0.05 \mathrm{~m} \mathrm{~s}^{-1}\right)$, drag forces were so small that on average no attenuation was observed for small shells (Fig. 3a). Medium-sized shells that were still fully within the meadow $\left(0.034 \mathrm{~m}^{2} ; 0.15 \mathrm{~m}\right.$ shell width) benefited from the protection the meadow offered at water speeds between 0.05 and $0.10 \mathrm{~m} \mathrm{~s}^{-1}$, with lower drag forces between 3.28 and $4.68 \mathrm{~N} \mathrm{~m}^{-2}$ (29-47\% of control values), but no clear attenuating effect was found at higher flow speeds where forces where between $8.18 \mathrm{~N} \mathrm{~m}^{-2}$ lower and $10.02 \mathrm{~N} \mathrm{~m}^{-2}$ higher than measured on bare sand $(86-114 \%$ drag forces compared to control values; $0.25-0.35 \mathrm{~m} \mathrm{~s}^{-1}$, Fig. 3b). For large shells $\left(0.054 \mathrm{~m}^{2} ; 0.19 \mathrm{~m}\right.$ shell width) protruding above the canopy, only the dense meadow clearly attenuated drag forces on the shell with a relief of on average $20.94( \pm 13.407 \mathrm{SE}) \mathrm{N} \mathrm{m}^{-2}$ (between $29 \%$ and $56 \%$ drag compared to control values), while medium density

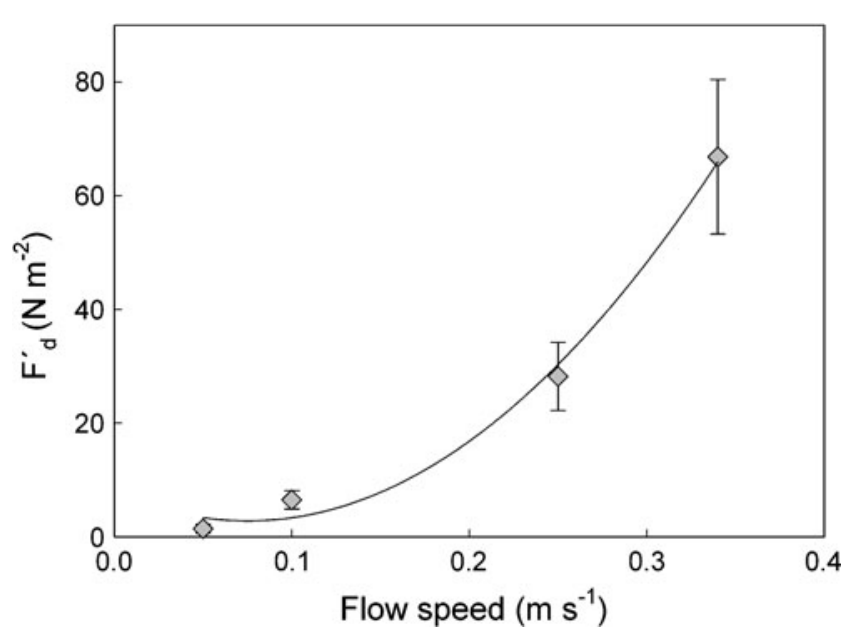

Fig. 2 Drag force $F_{\mathrm{d}}{ }^{\prime}$ (Newton per square meter) on bivalve shells mounted on bare sediment (no vegetation) at free stream flow speeds of $0.05,0.10,0.25$, and $0.34 \mathrm{~m} \mathrm{~s}^{-1}$. Values are averages $\pm \mathrm{SE}$ of five shells. The solid line shows the fitted quadratic regression equation $y=$ $7.9-135.44 x+9,000.56 x^{2}\left(R^{2}=0.99, p=0.08\right)$ meadows at times even aggravated the drag forces on the organism (Fig. 3c).

Waves Primarily, we confirmed an effect of wave regime on drag attenuation $(p=0.04)$, but the GLM had a poor fit $\left(\chi_{d f=4}^{2}=6.6 ; p=0.16\right)$. When we analyzed the two regimes independently, we found a significant effect of shell area $(p<0.001)$, but not meadow density $(p=0.69)$. When we examined the relationship between shell area and drag attenuation more closely, we found what appear to be different trends for different densities of the Posidonia meadow (Fig. 4). Solving a type II linear fit regression equation for zero drag attenuation $(y=0)$, we estimated a threshold area (square meter) for Pinna shells to profit from drag attenuation by the meadow, estimated as approximately $0.019 \mathrm{~m}^{2}$ under low-energy waves $\left(0.018 \mathrm{~m}^{2}, 0.013 \mathrm{~m}^{2}\right.$, and $0.028 \mathrm{~m}^{2}$ in a high, medium, and low-density meadow, respectively). The threshold shell area in high-density meadows was estimated as $0.017 \mathrm{~m}^{2}$ under high-energy wave regimes (Table 2). We hypothesize that Pinna shells under this threshold (average $<0.019 \mathrm{~m}^{2}$ ) are protected from large drag forces inside the meadow, while bigger shells $\left(>0.019 \mathrm{~m}^{2}\right)$ experience drag forces of $96-107 \%$ of drag forces on bare sand without a protective meadow at lowenergy wave regimes and $105 \%$ control values in a high density meadow at a high-energy wave regime.

When we use different shell orientations (i.e., resulting projected orthogonal surface to the flow), we do not see any differences in resulting drag forces per square meter (ANOVA; $F_{2,55}=0.40, p=0.67$ ) on the distinctly orientated shells. Therefore, we pooled the data, using exposed area as an equivalent to changes in effective surface of the organisms. We log-transformed the data, after which a linear relationship emerged between drag forces and shell surface for both wave regimes $(p<0.001)$ but not meadow density ( $p>0.44$; Fig. 5). Drag scales as on average the one third power of shell surface (slopes 0.29 and 0.34 for lowenergy and high-energy waves, respectively; Fig. 5).

\section{Discussion}

The results presented here confirm the role of seagrass meadows in sheltering $P$. nobilis from hydrodynamic forces and shows that the form in which hydrodynamic energy reaches seagrass meadows, e.g., as unidirectional flow or wave action, is crucial in determining the effect of the meadow on attenuating the drag forces experienced by bivalves. This is in agreement with the model results of Lowe et al. (2005) who found that waves (oscillatory flow) generate higher in-canopy flow when compared to unidirectional currents of the same magnitude. In meadows mainly 

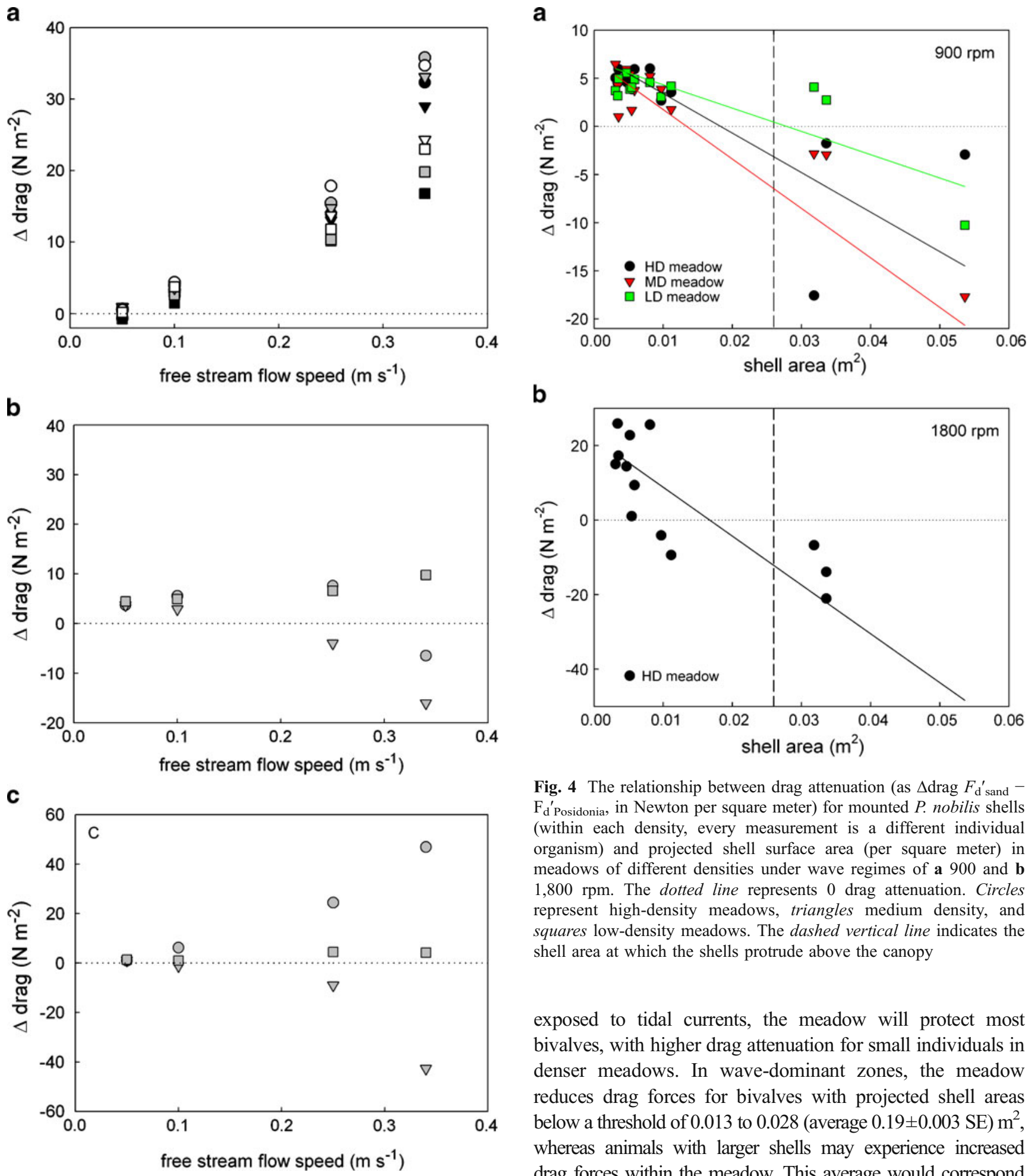

Fig. 3 The relationship between drag attenuation (as $\Delta \mathrm{drag} F_{\mathrm{d}}{ }^{\prime}$ sand $F_{\mathrm{d}}{ }^{\prime}$ Posidonia, in Newton per square meter) for mounted P. nobilis shells (individual shells have contrasting values on a gray scale) and flow velocity (in meter per second) in meadows of different densities for shell categories of $\mathbf{a}<0.011 \mathrm{~m}^{2} \mathbf{b} 0.034 \mathrm{~m}^{2}$, and $\mathbf{c} 0.054 \mathrm{~m}^{2}$. The dotted line represents 0 drag attenuation. Circles represent highdensity meadows, triangles medium density, and squares low-density meadows

Fig. 4 The relationship between drag attenuation (as $\Delta$ drag $F_{\mathrm{d}}$ sand $\mathrm{F}_{\mathrm{d}}{ }^{\prime}$ Posidonia, in Newton per square meter) for mounted $P$. nobilis shells (within each density, every measurement is a different individual organism) and projected shell surface area (per square meter) in meadows of different densities under wave regimes of a 900 and $\mathbf{b}$ $1,800 \mathrm{rpm}$. The dotted line represents 0 drag attenuation. Circles represent high-density meadows, triangles medium density, and squares low-density meadows. The dashed vertical line indicates the shell area at which the shells protrude above the canopy

exposed to tidal currents, the meadow will protect most bivalves, with higher drag attenuation for small individuals in denser meadows. In wave-dominant zones, the meadow reduces drag forces for bivalves with projected shell areas below a threshold of 0.013 to 0.028 (average $0.19 \pm 0.003 \mathrm{SE}$ ) $\mathrm{m}^{2}$, whereas animals with larger shells may experience increased drag forces within the meadow. This average would correspond to the area of a $P$. nobilis shell with a protrusion height of $0.16 \mathrm{~m}$, quite close $(85 \%)$ to the average leaf length $(0.19 \mathrm{~m})$ of the experimental meadows, and can be considered comparable if accounting for the bending angle of the canopies under flow. Hence, the experimental threshold size for P. nobilis individuals to benefit shelter from seagrass meadows is roughly equivalent to the canopy height. 
Table 2 Fitted orthogonal regression equations $y=a x+b$ of drag attenuation $(y$, Newton per square meter) vs. shell surface area $(x$, square meter) under wave regimes of 900 and $1,800 \mathrm{rpm}$ for experimental Posidonia oceanica meadows of different densities (HD, MD, LD) compared to Pinna nobilis shells mounted on unprotected bare sand

$a \quad b \quad$ Threshold area $\left(\mathrm{m}^{2}\right)$

\begin{tabular}{llll}
\hline 900 rpm & & & \\
HD & -410.8 & 7.525 & 0.018 \\
MD & -514.0 & 6.895 & 0.013 \\
LD & -242.1 & 6.750 & 0.028 \\
$1,800 \mathrm{rpm}$ & & & \\
HD & -1310.4 & 21.911 & 0.017
\end{tabular}

The last column gives the threshold shell area for $y=0(x=-b / a)$ where drag attenuation by the meadow is zero

In conclusion, large individuals that protrude from the canopy lack protection, and are thus more vulnerable to wave-induced damage. The latter especially applies to shallow sites where oscillatory water movements can easily protrude to the bottom. The influence of hydrodynamic facilitation of $P$. nobilis by Posidonia meadows might well explain the size distribution of fan mussel populations along the Spanish coast, with shallow sites being dominated by small individuals and large individuals being mostly observed in deeper or sheltered locations (García-March 2005)

The experimental conditions associated with flume dimensions have some limitations that need to be considered. The test section of the flume used here has a width of $0.6 \mathrm{~m}$ and a depth of $0.4 \mathrm{~m}$, which is relatively small compared to the largest sizes reached by both $P$. nobilis and $P$. oceanica. Shell widths of individuals in the field range from 0.03 to app. $0.27 \mathrm{~m}$, with the largest individuals exceeding the width that could be tested in the flume used here. The biggest bivalve tested protruded far above the canopy (at high unidirectional flow speeds) and reached up to three-fourth of the water depth of the canal. This led to wake formation behind the shell, and care should be taken to interpret the drag attenuation for the largest specimen as this wake formation could have influenced the results. Similarly, the leaf height of Posidonia shoots used here is relatively short, $0.19 \mathrm{~m}$, characteristic of the winter and spring period (Gobert et al. 2006), whereas canopies can reach $1 \mathrm{~m}$ in height in the late summer. However, during the minimum leaf height in the late winter, the largest $P$. nobilis individuals will protrude from the meadow and experience, therefore, risk of being dislodged by storms, relatively frequent at this time of the year. In contrast, hydrodynamic stress on P. nobilis should be lowest in the summer, when Posidonia density and canopy height are highest and storm activity is low.
Under uniform flow conditions, high-density meadows in general attenuated drag forces on large shells but had little attenuating effect at low velocities and medium shoot density, while at high water speeds, large shells suffered from increased drag due to the deflection of the plants and augmented flow speeds above the canopy (Fig. 3c). This increase in flow speed is due to the fact that seawater is an incompressible fluid, so that the volume flow rate $(Q)$, defined by the total velocity $(u)$ of the fluid that passes through a given cross-sectional area $A$ is conserved. Hence, if there is flow reduction within the canopy, in order to satisfy this principle, flow will speed up on top of the

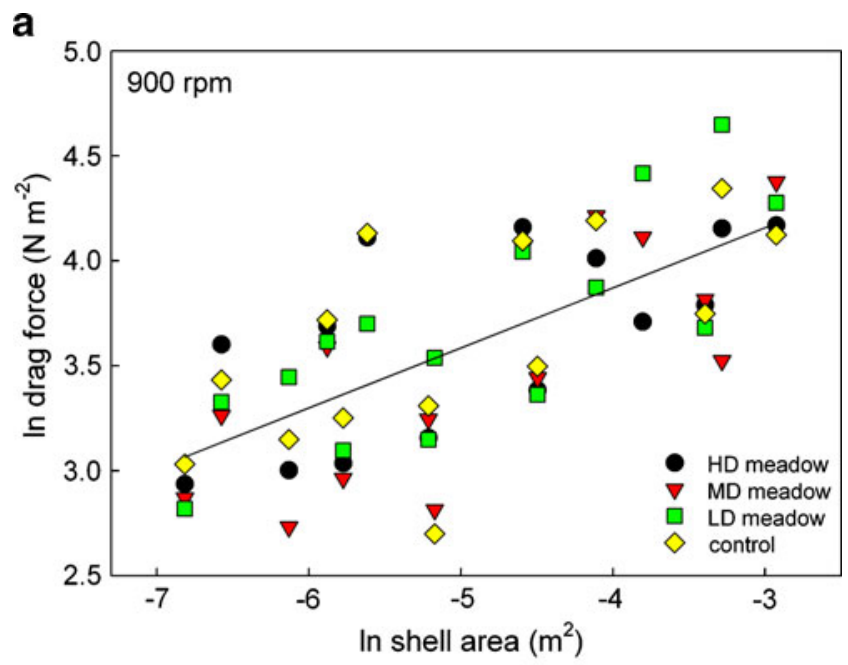

b

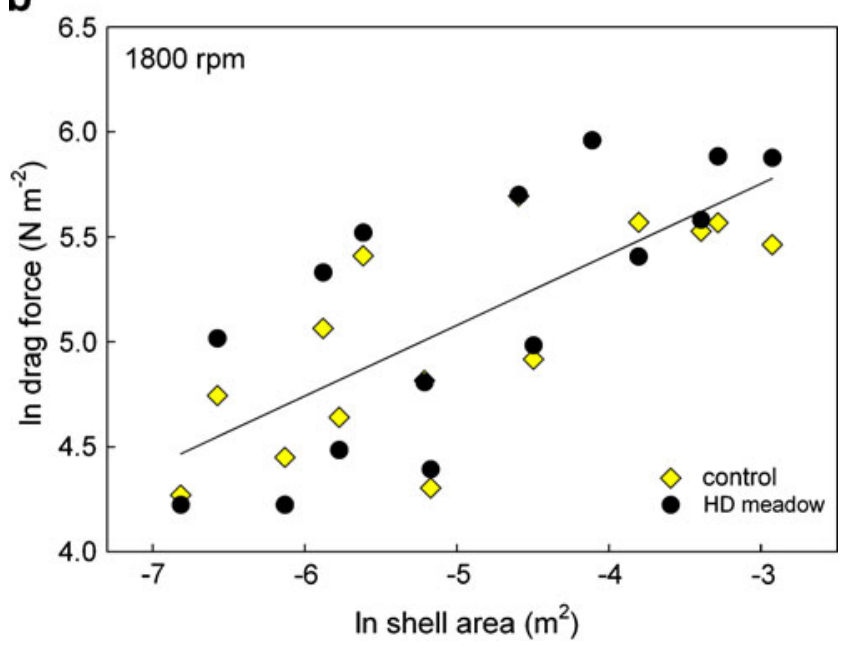

Fig. 5 The relationship between log transformed data of drag forces $\left(F_{\mathrm{d}}{ }^{\prime}\right.$, Newton per square meter) on $P$. nobilis shells in seagrass meadows of different densities and unprotected sediment (bare sand; control) with different shell orientations and thus exposed surface area (square meter) under wave regimes of $\mathbf{a} 900$ and $\mathbf{b} 1,800 \mathrm{rpm}$. Solid lines show the fitted regression equations: $900 \mathrm{rpm}$ control $y=0.26 x+4.91\left(R^{2}=\right.$ $0.40, p=0.015)$; $900 \mathrm{rpm} H D y=0.24 x+4.80\left(R^{2}=0.43, p=0.011\right)$; $900 \mathrm{rpm} M D y=0.33 x+5.10\left(R^{2}=0.57, p<0.01\right) ; 900 \mathrm{rpm} L D y=0.31 x+$ $5.24\left(R^{2}=0.57, p<0.002\right) ; 1,800 \mathrm{rpm}$ control $y=0.30 x+6.52\left(R^{2}=0.56\right.$, $p<0.002) ; 1,800 \mathrm{rpm} H D y=0.37 x+6.98\left(R^{2}=0.55, p<0.002\right)$ 
canopy. This increase in flow speeds above a canopy is common in experimental conditions, where the canopy occupies the width of the flume channel and there canal depth is limited, an example for P. oceanica and Cymodocea nodosa canopies in the same flume is described in Fig. 2 in Hendriks et al. (2010). Flow augmentation above the canopy also occurs in near shore situations when depth is limited and the seagrass meadow is extended over a large surface. At low meadow densities, the meadow might regain its protective effect due to increased porosity and increased flow speeds within the canopy and attenuates drag forces on large shells at all flow velocities.

Hydrodynamic forces decline exponentially with increasing depth, while seagrass density declines in parallel, and maximum bivalve size increases with increasing depth. The increased Posidonia shoot density in shallow waters may help compensate for the greater drag forces experienced by the organism, since the meadow effectively protects the smaller size class found at shallower depths. However, large shells do not benefit from attenuation by the meadow and therefore are limited to a depth range where drag forces are lower.

In addition to the shelter from hydrodynamic forces demonstrated here, growth of $P$. nobilis within $P$. oceanica meadows maybe enhanced by the increased sedimentary fluxes (Hendriks et al. 2008) and seston loads (Duarte et al. 1999) resulting from interactions between the seagrass canopy and suspended particles, which may increase food supply to support these large bivalves. Moreover, P. nobilis is also hidden from predators when confined within the dense canopies $P$. oceanica deploys.

When we use different orientations of the shells to increase the treatments of surface area, a negative picture for attenuation of drag forces by the meadow on Pinna shells emerges, as drag forces $\left(F_{\mathrm{d}}{ }^{\prime}\right.$, Newton per square meter) increase generally faster in meadow treatments compared to shells mounted on bare sand (Fig. 5). Only small shells would profit from the shelter. However, the dense meadow $\left(4,171\right.$ leaves $\left.\mathrm{m}^{-2}\right)$ has a similar increase of drag forces for increasing shell surface as under control circumstances; the drag forces are scaled to the one-fourth power of area. This indicates that dense meadow does offer protection under high-energy wave conditions.

Our results can be compared to field observations reported by García-March et al. (2007b). They calculated the drag forces $\left(F_{\mathrm{d}}\right)$ at deep $(13 \mathrm{~m})$ and shallow $(6 \mathrm{~m})$ sites to be between 0.7 and $20.6 \mathrm{~N}$ and 0.1 and $6.3 \mathrm{~N}$, respectively. According to these authors, the optimum $F_{\mathrm{d}}$ for $P$. nobilis would be $<9 \mathrm{~N}$, while the maximum dislodgement force withstood by the organism is approximately $45 \mathrm{~N}$. When we use their Table 2 to calculate $F_{\mathrm{d}}{ }^{\prime}$ (Newton per square meter) for the average shell sizes reported in their field sites, we arrive at $F_{\mathrm{d}}{ }^{\prime}$ values of $2.7-$
77.4 for the deep and 1.0-57.3 for the shallow site. Our test range $\left(F_{\mathrm{d}}{ }^{\prime}\right.$ from around $0-148 \mathrm{~N} \mathrm{~m}^{-2}$ for unidirectional flow and up to $290 \mathrm{~N} \mathrm{~m}^{-2}$ for wave action) encompasses these field ranges. Absolute forces on the shells stay well below the optimum $F_{\mathrm{d}}$ derived here (highest force measured $8 \mathrm{~N}$ ) under unidirectional flow but were exceeded under wave conditions (19 N), as estimated by these authors.

In summary, our results demonstrate that $P$. oceanica meadows provide shelter from hydrodynamic forces to $P$. nobilis but that this facilitation is highest in shallow meadows where the smaller animals remain within the canopy. Given these limitations on the shelter offered by $P$. oceanica meadows, we conclude that large Pinna individuals in shallow waters are vulnerable to water flow and at risk for dislodgement during storms, particularly in winter when low canopy heights imply that the meadow loses its protective capacity to attenuate drag forces on these bigger shells. Young, small individuals are effectively protected at high flow speeds but experience higher mortality to predators (Wu and Shin 1998). Seagrass meadows are in decline worldwide (Waycott et al. 2009). This decline is of particular concern because it also facilitates that of associated species, often endangered themselves (Hughes et al. 2009). The case of $P$. nobilis provides a clear illustration of this association: The decline of the seagrass meadows involves the reduction of the shoot density to levels where the canopy is no longer effective in reducing hydrodynamic drag forces rendering the bivalve more vulnerable to losses during periods of high wave action.

Acknowledgments This research was funded by the European Network of Excellence "Marine Biodiversity and Ecosystem Function" (MarBEF); FP6, EC contract no. 505446. Samples were collected with the permission of DG Medi Ambient, Mallorca. We would like to thank Bas Koutstaal for helping out with the experiment's logistics and Elvira Alvarez for collaboration and help in collecting shells.

Open Access This article is distributed under the terms of the Creative Commons Attribution Noncommercial License which permits any noncommercial use, distribution, and reproduction in any medium, provided the original author(s) and source are credited.

\section{References}

Ackerman, J.D., and A. Okubo. 1993. Reduced mixing in a marine macrophyte canopy. Functional Ecology 7: 305-309.

Bouma, T.J., M.B. De Vries, E. Low, G. Peralta, I.C. Tanczos, J. Van De Koppel, and P.M.J. Herman. 2005. Trade-offs related to ecosystem engineering: A case study on stiffness of emerging macrophytes. Ecology 86: 2187-2199.

Box, A., A. Sureda, and S. Deudero. 2009. Antioxidant response of the bivalve Pinna nobilis colonised by invasive red macroalgae Lophocladia lallemandii. Comparative Biochemistry and Physiology Part C: Toxicology \& Pharmacology 149: 456-460. 
Butler, A., N. Vicente, and B. De Gaulejac. 1993. Ecology of the pterioid bivalves Pinna bicolor Gmelin and Pinna nobilis L. Marine Life 3: 37-45.

Cabanellas-Reboredo, M., S. Deudero, and A. Blanco. 2009. Stableisotope signatures ( $\mathrm{d} 13 \mathrm{C}$ and $\mathrm{d} 15 \mathrm{~N})$ of different tissues of Pinna nobilis Linnaeus, 1758 (Bivalvia): Isotopic variations among tissues and between seasons. Journal of Molluscan Studies 75: 343-349.

Centoducati, G., E. Tarsitano, A. Bottalico, M. Marvulli, O. Lai, and G. Crescenzo. 2007. Monitoring of the endangered Pinna nobilis Linné, 1758 in the Mar Grande of Taranto (Ionian Sea, Italy). Environmental Monitoring and Assessment 131: 339-347.

Duarte, C.M., E. Benavent, and M.D. Sanchez. 1999. The microcosm of particles within seagrass Posidonia oceanica canopies. Marine Ecology-Progress Series 181: 289-295.

EEC. 1992. Council directive on the conservation of natural habitats and of wild fauna and flora (Natura 2000). 92/43/EEC. Official Journal of the European Communities. OJ L 206 of 22.07.1992

Gacia, E., and C.M. Duarte. 2001. Sediment retention by a Mediterranean Posidonia oceanica Meadow: The balance between deposition and resuspension. Estuarine, Coastal and Shelf Science 52: 505-514.

Galinou-Mitsoudi, S., G. Vlahavas, and O. Papoutsi. 2006. Population study of the protected bivalve Pinna nobilis (Linnaeus, 1758) in Thermaikos Gulf (North Aegean Sea). Journal of Biological Research 5: 47-53.

Gambi, M.C., A.R.M. Nowell, and P.A. Jumars. 1990. Flume observations on flow dynamics in Zostera marina (Eelgrass) beds. Marine Ecology Progress Series 61: 159-169.

García-March, J.R. 2005. Aportaciones al conocimiento de la Biología de Pinna nobilis Linneo 1758 (Mollusca: Bivalvia) en el litoral mediterráneo ibérico. Doctoral thesis, Universitat de Valencia, Spain.

García-March, J., A. García-Carrascosa, A. Peña Cantero, and Y.G. Wang. 2007a. Population structure, mortality and growth of Pinna nobilis Linnaeus, 1758 (Mollusca, Bivalvia) at different depths in Moraira bay (Alicante, Western Mediterranean). Marine Biology 150: 861-871.

García-March, J.R., L. Perez-Rojas, and A.M. Garcia-Carrascosa. 2007b. Influence of hydrodynamic forces on population structure of Pinna nobilis L., 1758 (Mollusca: Bivalvia): The critical combination of drag force, water depth, shell size and orientation. Journal of Experimental Marine Biology and Ecology 342: 202-212.

Gobert, S., M.L. Cambridge, B. Velimirov, G. Pergent, G. Lepoint, J. Bouquegneau, P. Dauby, C. Pergent-Martini, and D.I. Walker. 2006. Biology of Posidonia. In Seagrasses: Biology, ecology and conservation, ed. A.W.D. Larkum, R.J. Orth, and C.M. Duarte, 387-408. Netherlands: Springer.

Hemminga, M.A., and C.M. Duarte. 2000. Seagrass ecology. Cambridge: Cambridge University Press. ISBN 0-521-66184-6.

Hendriks, I.E., T. Sintes, T.J. Bouma, and C.M. Duarte. 2008. Experimental assessment and modeling evaluation of the effects of seagrass (Posidonia oceanica) on flow and particle trapping. Marine Ecology Progress Series 356: 163-173.

Hendriks, I.E., T.J. Bouma, E. Morris, and C.M. Duarte. 2010. Effects of seagrasses and algae of the Caulerpa family on hydrodynamics and particle-trapping rates. Marine Biology 157: 473-481.

Hughes, A.R., S.L. Williams, C.M. Duarte, K.L. Heck, and M. Waycott. 2009. Associations of concern: Declining seagrasses and threatened dependent species. Frontiers in Ecology and the Environment 7: 242-246.

Katsanevakis, S. 2007. Growth and mortality rates of the fan mussel Pinna nobilis in Lake Vouliagmeni (Korinthiakos Gulf, Greece): A generalized additive modelling approach. Marine Biology 152: 1319-1331.

Koch, E.W., and G. Gust. 1999. Water flow in tide- and wavedominated beds of the seagrass Thalassia testudinum. Marine Ecology Progress Series 184: 63-72.

Koch, E.W., J.D. Ackerman, J. Verduin, and M. Van Keulen. 2006. Fluid dynamics in seagrass ecology-from molecules to ecosystems. In Seagrasses: Biology, ecology and conservation, ed. A. W.D. Larkum, R.J. Orth, and C.M. Duarte, 193-225. The Netherlands: Springer.

Lowe, R.J., J.R. Koseff, and S.G. Monismith. 2005. Oscillatory flow through submerged canopies: 1. Velocity structure. Journal of Geophysical Research 110: C10016. doi:10.1029/2004JC00 2788.

Marbà, N., C.M. Duarte, J. Cebrian, M.E. Gallegos, B. Olesen, and K. Sand-Jensen. 1996. Growth and population dynamics of Posidonia oceanica on the Spanish Mediterranean coast: Elucidating seagrass decline. Marine Ecology Progress Series 137: 203-213.

Marba, N., C.M. Duarte, E. Diaz-Almela, J. Terrados, E. Alvarez, R. Martiinez, R. Santiago, E. Gacia, and A.M. Grau. 2005. Direct evidence of imbalanced seagrass (Posidonia oceanica) shoot population dynamics in the Spanish Mediterranean. Estuaries 28: 53-62.

Nepf, H.M. 1999. Drag, turbulence, and diffusion in flow through emergent vegetation. Water Resources Research 35: 479-489.

Nepf, H.M., and E.R. Vivoni. 2000. Flow structure in depth-limited, vegetated flow. Journal of Geophysical Research 105: 2854728557.

Peterson, C.H., R.A. Luettich, F. Micheli, and G.A. Skilleter. 2004. Attenuation of water flow inside seagrass canopies of differing structure. Marine Ecology Progress Series 268: 81-92.

Richardson, C.A., H. Kennedy, C.M. Duarte, D.P. Kennedy, and S.V. Proud. 1999. Age and growth of the fan mussel Pinna nobilis from south-east Spanish mediterranean seagrass (Posidonia oceanica) meadows. Marine Biology 133: 205-212.

Richardson, C.A., M. Peharda, H. Kennedy, and V. Onofri. 2004. Age, growth rate and season of recruitment of Pinna nobilis (L) in the Croatian Adriatic determined from $\mathrm{Mg}: \mathrm{Ca}$ and $\mathrm{Sr}: \mathrm{Ca}$ shell profiles. Journal of Experimental Marine Biology and Ecology 299: 1-16.

Waycott, M., C.M. Duarte, T.J.B. Carruthers, R.J. Orth, W.C. Dennison, S. Olyarnik, A. Calladine, J.W. Fourqurean, K.L. Heck, A.R. Hughes, G.A. Kendrick, W.J. Kenworthy, F.T. Short, and S.L. Williams. 2009. Accelerating loss of seagrasses across the globe threatens coastal ecosystems. PNAS 106: 1237712381.

Wu, R.S.S., and P.K.S. Shin. 1998. Transplant experiments on growth and mortality of the fan mussel Pinna bicolor. Aquaculture 163: $47-62$.

Zavodnik, D., M. Hrs-Brenko, and M. Legac. 1991. Synopsis on the fan shell Pinna nobilis L. in the eastern Adriatic Sea. In Les Especes Marines a Protéger en Méditerranée, ed. C.F. Boudourescque, M. Avon, and V. Gravez, 169-178. Marseille: GIS Posidonie. 